\title{
Physiological and biomechanical adaptations to the cycle to run transition in Olympic triathlon: review and practical recommendations for training
}

\author{
Gregoire P Millet, Veronica E Vleck
}

\begin{abstract}
Current knowledge of the physiological, biomechanical, and sensory effects of the cycle to run transition in the Olympic triathlon $(1.5 \mathrm{~km}, 10 \mathrm{~km}, 40 \mathrm{~km})$ is reviewed and implications for the training of junior and elite triathletes are discussed. Triathlon running elicits hyperventilation, increased heart rate, decreased pulmonary compliance, and exercise induced hypoxaemia. This may be due to exercise intensity, ventilatory muscle fatigue, dehydration, muscle fibre damage, a shift in metabolism towards fat oxidation, and depleted glycogen stores after a $40 \mathrm{~km}$ cycle. The energy cost $\left(C_{R}\right)$ of running during the cycle to run transition is also increased over that of control running. The increase in $\mathrm{C}_{R}$ varies from $1.6 \%$ to $11.6 \%$ and is a reflection of triathlete ability level. This increase may be partly related to kinematic alterations, but research suggests that most biomechanical parameters are unchanged. A more forward leaning trunk inclination is the most significant observation reported. Running pattern, and thus running economy, could also be influenced by sensorimotor perturbations related to the change in posture. Technical skill in the transition area is obviously very important. The conditions under which the preceding cycling section is performed-that is, steady state or stochastic power output, drafting or non-drafting-are likely to influence the speed of adjustment to transition. The extent to which a decrease in the average 10 km running speed occurs during competition must be investigated further. It is clear that the higher the athlete is placed in the field at the end of the bike section, the greater the importance to their finishing position of both a quick transition area time and optimal adjustment to the physiological demands of the cycle to run transition. The need for, and current methods of, training to prepare junior and elite triathletes for a better transition are critically reviewed in light of the effects of sequential cycle to run exercise.
\end{abstract}

(Br F Sports Med 2000;34:384-390)

Keywords: triathlon; cycle to run transition; training; performance
Table 1 Triathlon race distances $(\mathrm{km})$

\begin{tabular}{llll}
\hline Distance & Swim & Bike & Run \\
\hline Long & 3.8 & 180 & 42 \\
Middle & 2.5 & 80 & 20 \\
Triathlon /Olympic/classic or short & 1.5 & 40 & 10 \\
Sprint & 0.75 & 20 & 5 \\
\hline
\end{tabular}

The sport of triathlon comprises a sequential swim, cycle, and run over a variety of distances (table 1). Triathlon has evolved considerably since its inception in the late 1970s, with the most significant change being the introduction of draft-legal races for the elite. Of these, the $1.5 \mathrm{~km}$ swim, $40 \mathrm{~km}$ cycle, $10 \mathrm{~km}$ run Olympic triathlon or triathlon distance event will debut at the Sydney 2000 Olympics.

Several investigators ${ }^{1-7}$ have indicated that the main requisites for successful triathlon performance are high maximal oxygen uptake ( $\left.\mathrm{VO}_{2} \mathrm{MAX}\right)$, lactate threshold, and maximum sustainable percentage of $\dot{\mathrm{VO}}_{2} \mathrm{MAX}$, as well as a low energy cost of exercise for each discipline. The relation between these variables measured separately in each discipline and triathlon performance is not as high, however, as seen in the respective single sports. Prior exercise affects the strength of the correlation between physiological variables specific to one discipline and performance in it under conditions characteristic of triathlon competition. ${ }^{8-11}$ The ability to link the three triathlon disciplines in an optimal manner is an important determinant of success. ${ }^{6}{ }^{12}$

Margaritis ${ }^{13}$ states that "the physiological conditions in which the first transition is made can limit performance in the two following events"; this is also the case for the second transition. Little research ${ }^{14}{ }^{15}$ has been carried out on the first, swim to cycle, transition. Within nondrafting races, the first transition is regarded as having a negligible effect on overall performance. The second, cycle to run, transition is traditionally considered as more important to overall 1.5 $\mathrm{km}, 40 \mathrm{~km}, 10 \mathrm{~km}$ performance. It has therefore been the subject of more research. ${ }^{12}{ }^{16-21}$

The aim of this article is to review current knowledge of the physiological, biomechanical, and sensory effects of the cycle to run transition in the Olympic triathlon event on junior and elite triathletes, and to outline the resultant training implications. For these purposes the cycle to run transition is defined as 
Table 2 Swim, swim to cycle transition (T1), cycle, cycle to run transition area (T2), and run times (h.min.s), and expressed as a percentage of overall time, achieved by elite and junior male triathletes for 1997 and 1998 Triathlon World Championship competition

\begin{tabular}{lll}
\hline & Elite & funior \\
\hline Total time & $02: 00: 39(04: 49)$ & $02: 06: 54(07: 27)$ \\
$1.5 \mathrm{~km}$ swim & $18: 57(00: 51)$ & $20: 02(01: 17)$ \\
Percentage & $16.1(1.1)$ & $15.8(0.9)$ \\
(T1) swim to cycle & $01: 12(00: 16)$ & $01: 22(00: 19)$ \\
Percentage & $1.0(0.2)$ & $1.3(0.4)$ \\
40 km cycle & $01: 03: 23(03: 54)$ & $01: 07: 03(04: 01)$ \\
Percentage & $53.7(1.3)$ & $52.9(1.2)$ \\
(T2) cycle to run & $00: 56(00: 09)$ & $01: 23(03: 52)$ \\
Percentage & $0.8(1.1)$ & $1.1(3.3)$ \\
10 km run & $33: 22(02: 05)$ & $37: 24(03: 18)$ \\
Percentage & $28.3(0.9)$ & $29.4(1.5)$ \\
\hline
\end{tabular}

Values are mean $(\mathrm{SD})$.

the period from the last kilometre of the cycle section through to the end of the first kilometre of the run. The transition area is defined as the clearly demarcated section at the start of which athletes must dismount their cycles. They then run, either barefoot or with cycling shoes on, to rack their cycle at a defined location before taking off their helmet, putting on their running shoes, and leaving the clearly marked transition area exit to commence the run section.

\section{Technical and tactical features of the cycle to run transition}

Despite the fact that "the layout of (both) transitions must provide equal advantage to all competitors" (European Triathlon Union Operations Manual, 1999), the need to avoid collisions or jams means that it is crucial for an athlete to arrive in the transition area at the front of a group. Although no published data are available to support this assertion, anecdotal reports suggest that performers therefore often increase their speed during the last kilometre of the cycle section (French and British Olympic squad members, personal communications, 1999). At World Championships, the mean (SD) time spent within the entire demarcated transition area is 0:56 (0:09) min.s for elite male triathletes and 01:23 (03:52) min.s for junior male triathletes (table 2). The best triathletes use less than eight seconds of this time for racking their cycle, taking

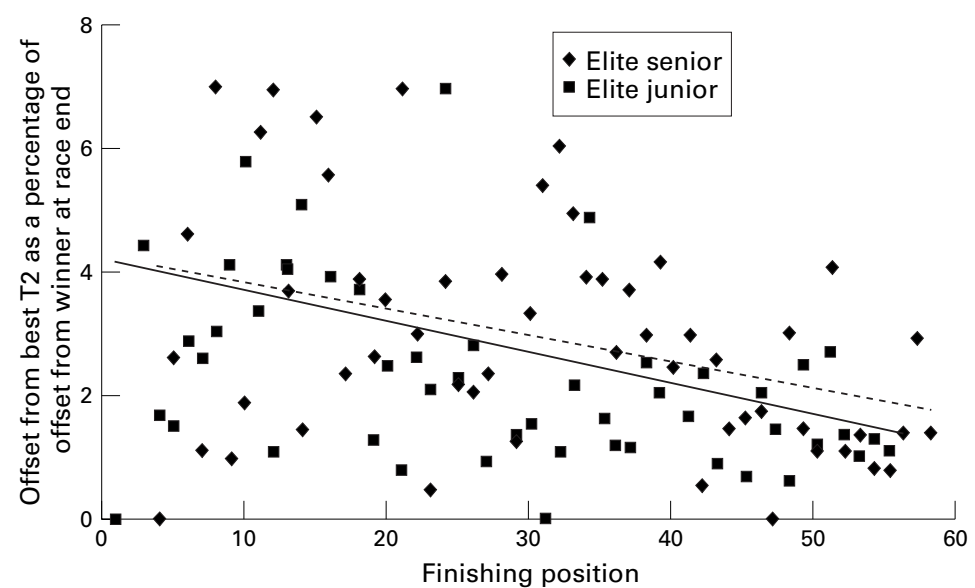

Figure 1 Offset from fastest cycle to run transition time (T2) expressed as a percentage of eventual offset from the winner in each category $v$ finishing position for elite senior and junior male triathletes competing in the 1997 World Triathlon Championships. off their helmet, and putting on their running shoes. Although total time spent in the transition area varies between events because of a lack of standardisation in its length, it only accounts for between $0.8 \%$ and $1.3 \%$ of total race time (table 2). Moreover, Pfützner et $a l^{1}$ have observed in the field that $70 \%$ of national squad triathletes then remain up to $10 \%$ below their average $10 \mathrm{~km}$ running speed over the first 500-1000 $\mathrm{m}$ of the run, losing up to a further 20 seconds. $^{21}$ These data are as yet unsupported by experimental research. Data comparing running speeds achieved within the first kilometre of the run during Olympic triathlon competition, when the athlete is undergoing physiological, biomechanical, and sensorimotor adjustment to the cycle to run transition, with running speeds achieved during the second kilometre onwards have not as yet been published. It remains clear, however, that the higher the athlete is placed in the field at the end of the cycling section, the greater the importance to their final finishing position of both a quick transition area time (fig 1) and optimal adjustment to the physiological demands of the cycle to run transition.

\section{Physiological changes}

Laboratory data indicate that triathlon running is harder than control running at the same speed. Oxygen consumption $\left(\dot{\mathrm{V}}_{2}\right)$, respiratory frequency, ventilation rate, and heart rate are increased (table 3). Several authors ${ }^{12}{ }^{22}{ }^{23}$ have proposed that the observed increase in oxygen consumption during triathlon running over that for control running is partly due to glycogen depletion during the $40 \mathrm{~km}$ cycle. Such depletion may engender a shift in metabolism towards fat oxidation. The hyperventilation and decreased ventilatory efficiency observed during transition may be explained by ventilatory muscle fatigue during the first seven minutes of the run, ${ }^{12}$ by decreased pulmonary compliance, and by exercise induced hypoxaemia. ${ }^{24}$ The increase in heart rate over control conditions may be attributed partially to dehydration ${ }^{1822}{ }^{23}$ with concomitant haemoconcentration, decreased stroke volume, and higher rectal temperature. ${ }^{3}$ The cycle to run transition induces leg muscle fatigue ${ }^{17} 182025$ and a redistribution of muscle blood flow between the different muscle groups. ${ }^{26}$

Energy cost of running $\left(\mathrm{C}_{\mathrm{R}}\right.$, expressed in $\mathrm{ml} \mathrm{O}_{2} / \mathrm{kg}$ per $\mathrm{km}$ ) is $1.6 \%$ to $11.6 \%$ higher during a cycle to run transition than that of control running. ${ }^{3} 12172223$ The extent to which energy cost is increased is influenced by the conditions under which the athlete has completed the preceding $40 \mathrm{~km}$ cycle. Research has shown that, whether a preceding cycle is performed under drafting or non-drafting conditions and whether it is conducted at steady state or variable power outputs, will influence performance over a $10 \mathrm{~km}$ triathlon run as a whole. ${ }^{27}$

Hausswirth et $a l^{27}$ have shown that running after a cycle under steady state drafting conditions is certainly easier than that after a cycle under non-drafting conditions. Eight elite male triathletes performed a $5 \mathrm{~km}$ run, and a 
Table 3 Physiological, biomechanical, and sensorimotor effects of running after a cycle to run transition, as compared with isolated running, in triathletes

\begin{tabular}{|c|c|c|c|}
\hline Subjects & Protocol & Effect & Reference \\
\hline $\begin{array}{l}13 \text { female duathletes } \\
\& \text { triathletes }\end{array}$ & $\begin{array}{l}\text { Measurement of running economy at } 169,177,196 \\
\text { and } 215 \mathrm{~m} / \mathrm{min} \text { and run at } \dot{V}_{2} \mathrm{MAX}_{\text {MAring control }} \\
\text { running } v \text { after } 45 \mathrm{~min} \text { cycling at } 70 \% \dot{\mathrm{V}}_{2} \mathrm{MAX}\end{array}$ & $\begin{array}{l}\uparrow \text { running economy }(\mathrm{p}<0.02) \text { at each test velocity after } \\
\text { cycling }\end{array}$ & Danner and Plowman ${ }^{17}$ \\
\hline 5 men & 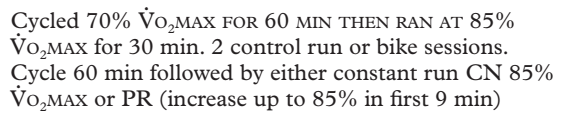 & $\begin{array}{l}\mathrm{CR}: \uparrow \dot{\mathrm{V}}_{2}, \dot{\mathrm{V}} \mathrm{E}, \mathrm{HR} \text { than } \mathrm{C}_{\mathrm{R}} \\
\mathrm{PR} \text { strategy did } \downarrow \text { work in first } 9 \text { min but induced } \downarrow \\
\dot{\mathrm{V}}_{2}, \dot{\mathrm{V}}, \mathrm{HR} \text { and } \mathrm{BLA} \text { in rest of run than CR. }\end{array}$ & Kreider $e t a l^{6}$ \\
\hline 5 triathletes & $\begin{array}{l}\text { Filmed at } 1,5 \text {, and } 9 \mathrm{~km} \text { into } 10 \mathrm{~km} \text { run after warm } \\
\text { up or after } 40 \mathrm{~km} \text { cycle }\end{array}$ & $\begin{array}{l}\text { Run speed } \downarrow \text { after bike }(\mathrm{p}<0.05) \text { though no difference in } \\
\text { run velocity or stride length at the intervals. Trend to } \downarrow \\
\text { stride length after bike (NS). } \uparrow \text { internal mechanical } \\
\text { work. No significant difference in passive energy } \\
\text { exchange or rate of energy exchange in the run } \\
\text { mechanics between the two conditions }\end{array}$ & Marino and Goegan ${ }^{25}$ \\
\hline 12 men & & $\begin{array}{l}\text { Prior swim and bike } \uparrow \dot{\mathrm{V}}_{2}, \dot{\mathrm{V}} \mathrm{E}, \mathrm{HR} \text { and ventilatory } \\
\text { efficiency (all NS) }\end{array}$ & Miura $e t a l^{10}$ \\
\hline 11 men & $\begin{array}{l}1.5 \mathrm{~km} \text { swim }+40 \mathrm{~km} \text { run }+10 \mathrm{~km} \text { run } \\
1 \text { week later did control } 10 \mathrm{~km} \text { run }\end{array}$ & $\begin{array}{l}\uparrow \text { mean } \dot{\mathrm{VO}}_{2} \\
\uparrow \text { fraction of } \dot{\mathrm{VO}}_{2} \mathrm{MAX} \text { used } \\
\uparrow \text { mean } \dot{\mathrm{V}} \mathrm{E}, \mathrm{HR} \text {, and lactate at end of both runs NS } \\
\downarrow \text { running efficiency }\end{array}$ & Guezennec et al ${ }^{2}$ \\
\hline $\begin{array}{l}4 \text { triathletes, } 3 \\
\text { duathletes }\end{array}$ & $\begin{array}{l}\text { (30 min swim, } 60 \text { min bike, } 45 \mathrm{~min} \text { run) or } 45 \mathrm{~min} \text { run } \\
\text { at triathlon run speed. Swim to cycle transition of } 5 \\
\text { min; cycle to run transition of } 8 \text { min. triathlon run at } \\
60 \% \text { HRmax } 20 \text { min then } 80 \% \text {. }\end{array}$ & $\begin{array}{l}\uparrow \text { in } \mathrm{C}_{\mathrm{R}} \\
\downarrow \text { stride length immediately after cycling } \\
\text { mean stride length unchanged }\end{array}$ & Hausswirth et al ${ }^{23}$ \\
\hline 7 men & As in Hausswirth et al ${ }^{23}$ & $\uparrow$ forward leaning posture after cycling & Hausswirth $e t a l^{18}$ \\
\hline $\begin{array}{l}8 \text { elite, } 8 \text { subelite, } \\
\text { mixed sex }\end{array}$ & $\begin{array}{l}\text { Two } 7 \text { min runs at speed same as sustained during } \\
\text { triathlon before and after max cycle exercise } C_{R} \text { and } \\
\text { external mechanical cost of running evaluated during } \\
\text { last min of each run. }\end{array}$ & $\begin{array}{l}\text { Triathlon ability level related to change in energy cost } \\
\text { after bike }(\mathrm{p}<0.01) \text {. Effect of cycling on respiratory } \\
\text { muscle } \mathrm{O}_{2} \text { demand more important }(\mathrm{p}<0.05) \text { for } \\
\text { subelite than elite. Tendency to } \downarrow \text { mechanical cost } \\
\text { associated with better leg stiffness regulation in elites }\end{array}$ & Millet $e t a l^{31}$ \\
\hline
\end{tabular}

Key: $\uparrow$ increase; $\downarrow$ decrease; $\dot{\mathrm{V} E}$, ventilation (litres/min); HR, heart rate (beats/min); BLA, blood lactate concentration; HR=max, maximal heart rate; $\dot{\mathrm{V}}_{2} \mathrm{MAx}, \mathrm{maxi}-$ mal oxygen uptake; $C_{R}$, energy cost of running; $C R$, constant run; PR, progressive run; NS, non-significant at the $95 \%$ confidence limit.

$0.75 \mathrm{~km}, 20 \mathrm{~km}, 5 \mathrm{~km}$ non-drafting triathlon. Three days later they performed the same triathlon under drafting conditions, cycling at the same speed as in the first triathlon. For a similar performance time and effort during the swim and identical speed during the cycle, oxygen uptake, ventilation, heart rate, and blood lactate values were all lower during the drafted cycle. Steady state cycling in a sheltered position during the entire cycle of a triathlon led to a considerable reduction in the required energy expenditure at a given speed, and created the conditions for decreased physiological stress at the onset of the triathlon run. ${ }^{27}$

Smith $^{28}$ obtained preliminary power output data in the field for elites competing in a draftlegal World Cup event on the Olympic circuit. Their data illustrated that draft-legal elite cycling tends to be conducted at variable rather than at steady state power outputs, in order to "bridge gaps, maintain contact with a pack and/or contribute to the overall speed of the lead or chasing packs". Wide variation in mean power output, velocity, and cadence was noted over the cycle section $(238.3$ (167.4) W or $3.9(2.8) \mathrm{W} / \mathrm{kg}, 39.8(8.3) \mathrm{km} / \mathrm{h}$, and 76.3 (28.3) $\mathrm{rpm}$ in one male triathlete). Williams et $a l^{29}$ have shown that part of $\mathrm{C}_{\mathrm{R}}$ results directly from skeletal muscle metabolism. Boone and Kreider $^{16}$ noted $C_{R}$ to be increased by $5.7 \%$ and $8.7 \%$ over a control run when it was preceded by 10 minutes of steady state cycling at $60 \%$ and $80 \%$ of maximal oxygen uptake respectively. Little is known, however, about the effects of cycling intensity on the energy cost of subsequent running. Even less is known about the repercussions of stochastic effort-for example, an increase in speed over the last kilometre of the cycle in order to attain a good position when entering the transition area-for the cycle-run transition. Both of these issues are of the highest practical interest for triathlon training and race tactics. ${ }^{28}$ More research is required on the effects of the conditions under which the preceding cycle is carried out on the physiological stress of the triathlon transition.

\section{Biomechanical modifications}

The increase in energy cost of running may be related to alterations in biomechanics, as it has been reported in isolated running among triathletes. ${ }^{30}$ Marino and Goegan ${ }^{25}$ showed that five athletes filmed during a $10 \mathrm{~km}$ run after a $40 \mathrm{~km}$ cycle underwent increased internal mechanical work (+ 54\% at $9 \mathrm{~km}$ ) and ran more slowly $(-38 \%)$ than they did during a control $10 \mathrm{~km}$ run at race pace. Guezennec et $a l^{2}$ also showed an $8 \%$ decrease in running efficiency over the control, run only, condition during a $10 \mathrm{~km}$ run after completion of both a $1.5 \mathrm{~km}$ swim and $40 \mathrm{~km}$ cycle. This finding was confirmed by Hausswirth et al. ${ }^{23}$ Kinematic variables that could partly explain modifications in running economy include stride length, trunk gradient, knee angle in the non-support phase, and knee extension during the stance phase. ${ }^{18}$

Loss of coordination is experienced during the transition by novice triathletes. The phenomenon has been attributed to the change in typical frequency from cycling to running $(1.5-2.0 \text { to } 1-1.5 \mathrm{~Hz})^{19}$ and/or the change from a non-weight-bearing activity to one associated with impact forces of two to three times body mass. ${ }^{18}{ }^{19}$ Such loss of coordination does not occur in elite triathletes to an extent that they are subjectively aware of. ${ }^{31}$ Whether this is the 
case for juniors is not clear. Some authors indicate that stride length or frequency is unchanged during running after a cycling bout. ${ }^{12} 19{ }^{23}$ Hip or ankle vertical oscillation and thigh, knee, or trunk angle at different phases of stance or flight time are also unchanged..$^{18} 193132$ During eccentric contractions, the fatigue results in a decrease in the energy stored in muscle structure and lowers the efficiency of the stretch shortening movements like running. ${ }^{33}$ Other authors have observed a significant decrease in stride length over a triathlon run ${ }^{18}{ }^{25}$ and attributed it to local muscle fatigue from the preceding cycle. Witt ${ }^{20}$ reported a perturbation in electromyographic activity of the vastus lateralis, tibialis anterior, and tensor fascia latae, related to the change from concentric muscular contraction in cycling to a stretch shortening cycle activity in running, and to an alteration in motor unit recruitment. Hausswirth et $a l^{18}$ also observed a more forward leaning posture, affecting running efficiency, to be adopted by triathletes during the cycle to run transition. This change in trunk gradient may be due to modifications in abdominal and lumbar muscle contraction induced by novel sensory afferent input with the change of body position between cycling and running.

\section{Sensory adaptations}

Little is known about the effect of the change in posture from cycling to running on the maintenance of equilibrium. Normally balance is maintained by the response of the integrator centres in the brain to feedback from the otholithic, visual, and somatosensory systems. Such feedback is likely to differ between the activities of cycling and running. For example, field motion falls from 50 to $70 \%$ between cycling and running. Lepers et $a l^{34}$ found that adaptation to proprioceptive feedback from prolonged (stationary) cycling or running in triathletes persists for a short period after cessation of each of these activities. This would suggest that postural compensation at the start of the cycle to run transition may be out of phase with actual neurosensory feedback. Muscle fatigue and/or glycogen depletion from the preceding run would increase impairment of the effectiveness of the postural regulation loop, as would any redistribution of blood flow with the change in activity.

It is suggested that some of the biomechanical changes observed with the cycle to run transition-that is, hip movement or step asymmetry - may be attributed to a lag in the neurosensory adaptive process to these activities. The time required for complete adjustment to the change from cycling to running, and the effect of this on running mechanics and economy, is probably specific to the individual.

\section{Implications for performance}

Various authors have suggested that the extent to which $\mathrm{C}_{\mathrm{R}}$ is perturbed during triathlon running reflects triathlete ability level. ${ }^{11} 121731$ The more experienced the triathlete, the less mechanical and physiological alterations appear to occur during transition over the control, run only, condition. Millet et $a{ }^{\beta 2}$ observed that $C_{R}$ increased after a maximal cycle test by $5.2 \%$ over control conditions in junior French national squad athletes, but remained unchanged in the elites. Zderic et a ${ }^{35}$ showed that triathletes with slower combined cycle and run times for non-drafting triathlon than other athletes tended to have more difficulty with the transition from cycling to running. They exhibited a greater percentage change in the energy used during a 20 minute triathlon run trial (involving a 40 minute cycle, one minute cycle to run transition, and a 20 minute run) over a 20 minute run only trial.

Zderic et $a l^{35}$ also showed that the combined cycle and run time for a triathlon competition was best predicted by variables that incorporated cycling power and changes in running economy after the transition. The relative influence of steady state and stochastic power output during the cycle-for example, increased speed over the final kilometre-on performance in transition is unclear. Palmer et a ${ }^{36}$ have shown a reduction in $20 \mathrm{~km}$ cycle time trial performance after 150 minutes of stochastic cycling at 58 (12)\% peak power output compared with performance after 150 minutes of steady cycling at the same power output. Whether Palmer's data have any application to $10 \mathrm{~km}$ running after a $40 \mathrm{~km}$ draft-legal cycle is not clear.

Running performance is certainly improved after a cycle under steady state drafting conditions over that on completion of a non-drafting cycle leg. ${ }^{27}$ Cycling in a sheltered position during the entire cycle of a triathlon leads to a considerable reduction in the required energy expenditure at a given speed, and creates the conditions for a better performance in the run. $^{27}$

\section{Tactical implications}

It appears that the first minute of transition running may be characterised by the paradox of increased energy demand in conjunction with decreased exercise efficiency. In theory, the ideal solution to this situation would be to increase speed gradually from the onset of the triathlon run until ventilatory, cardiovascular, and neuromuscular steady state is attained. ${ }^{3162637}$ Such tactics are not practicable within high level competition. The ability to minimise time lost in the transition area while dismounting and racking the cycle, taking off the helmet, and putting on the running shoes can be crucial to the final finishing position. This is particularly so at the top end of the field. For example, at the 1997 World Championships, Chris McCormack took the lead over his opponents with a gap of eight seconds earned in the transition area, and was never caught. Less trained triathletes have less developed technical skills specific to the transition area. They may experience a greater decrement in performance over the first kilometre of the run than their more successful counterparts. Athletes with good transition 
skills may also avoid the common mistake of starting the run at a faster pace than they can sustain, and then weakening on the final $5 \mathrm{~km}$. The question of ideal tactics cannot be answered conclusively until more research is available on the influence of the conditions under which the preceding cycle is carried out, on the duration of physiological, biomechanical, and sensorimotor adjustment to subsequent running. The ramifications of transition performance for overall finishing position of elite and junior triathletes must also be more clearly elucidated.

Training implications for elite triathletes The literature implies that the ability to link the cycle and run sections of the triathlon efficiently is crucial to race performance. No consensus currently exists, however, on the need to practice back to back cycle-run training. The five times and current World Champion Simon Lessing, for example, does not include such sessions within his training programme. Of 30 members of the 1996 Great Britain national elite squad, 27 follow suit (V E Vleck, unpublished work).

Nevertheless, various different back to back training methods exist. The first is based on long (two to four hour) aerobic sessions in both disciplines. This type of session is used mainly by triathletes who compete in middle distance or long distance triathlons. The aim of such sessions is to accustom the athlete to, and lessen the discomfort of, running after cycling while in a near glycogen depleted state. The relevance of such sessions to Olympic triathlon racing is unclear. The second method uses lower intensity exercise in one discipline as recovery work from higher intensity effort in the other. The proposed advantages of this method are a lower risk of running injury because of decreased overall mileage and limiting of "junk" (running) mileage. ${ }^{38}$ The use of cross training as a mechanism of injury prevention is not currently justified by the triathlon injury literature, however. ${ }^{39}$ The third method of back to back training involves short duration cycle-run efforts at or over race speed. Field evidence suggests that this is an efficient way to prepare triathletes to perform well over the start of the run section of an Olympic distance race. Data suggesting that elite triathletes do not experience an increase in $\mathrm{C}_{\mathrm{R}}$ over control running during the cycle to run transition ${ }^{31} 32$ must be consolidated by studies involving larger sample sizes and by tests with high ecological validity. The premise advanced by Pfützner et $a l^{21}$ that $70 \%$ of elites remain below their average running speed for the $10 \mathrm{~km}$ over first $0.5-1 \mathrm{~km}$ of triathlon competition needs to be verified. Whether the stride patterns of elite triathletes are significantly altered under the influence of cycling fatigue, ${ }^{18} 193132$ and therefore whether back to back training for $1.5 \mathrm{~km}, 40 \mathrm{~km}, 10 \mathrm{~km}$ triathlon is justified on biomechanical grounds, must be researched further. Experimental evidence that back to back training will decrease any increment in the physiological cost of transition running incurred over that of control running is also required. The validity of triathlon cycle to run transition training in elite triathletes, and the optimal methods of undertaking such training, require further investigation.

\section{Training implications for juniors}

Juniors are likely to benefit from the (careful) integration of back to back sessions into their training programme. ${ }^{32}$ Three different approaches to back to back sessions exist. The need to build up a general endurance base first in the immature athlete is paramount in the first approach ${ }^{40}$ which discourages the introduction of intensive brick training sessions at this age. The second approach involves the use of very short intensive interlinked cycling, running, and even swimming sessions. It is highly developed in Australia by virtue of the existence of a professional race series conducted under similar formats-for example, the "Formula One" triple supersprint involving three back to back $0.3 \mathrm{~km}, 7 \mathrm{~km}, 2 \mathrm{~km}$ triathlons. The third approach involves the use of technical workouts. The aims of such sessions are to improve mechanical efficiency to limit alterations in stride pattern after cycling.

Several such back to back sessions may be used in the training of junior triathletes. ${ }^{41}$ These include drills to: (a) limit the persistence time of adaptation to visual input regarding field motion-for example, the "speed contrast" session, involving major differences in speed between a downhill cycle and the subsequent climbing running bout; $(b)$ develop sensitivity to somatosensory information-for example, the "blind transition" session, in which cycling on a turbotrainer and running drills are linked together with the eyes closed; (c) accustom to change of posture and redistribution of blood flow-for example, the "posture contrast" session, in which several postures are linked within the same training session (seated cycling; cycling out of the saddle; running; swimming; aqua-jogging, etc); (d) develop technical skill in the transition area-for example, the "flash transitions" session, in which only the time in the transition area is measured; (e) develop appropriate stride technique in the case of pre-existing muscular fatigue - for example, the "drills on fatigue" sessions, in which cycling in a big gear (on a hill or on a turbotrainer) and running drills are linked; $(f)$ develop an aerobic base with plenty of cycle to run transitions - for example, the "bike and run" sessions, in which two juniors of the same height share the same bicycle, one cycling, and one running.

Emphasising the sensory and technical features of the transition in the training of juniors is aimed at increasing their speed of adaptation to it, and thus improves their running economy off the cycle. The above sessions also aim to improve the feeling of comfort at the first stages of triathlon development. Acquisition of specific technical skill should precede introduction of intensive back to back training sessions into the 
triathletes' training schedule. ${ }^{41}$ The back to back sessions at or above race pace are extremely tiring. They must be used with caution in the training of immature triathletes, if negative over-reaching and/or overtraining are to be avoided.

\section{Directions for future research}

Before athletes and coaches can be sure that they are preparing for drafting races in an optimal manner, further investigation is required: (a) to determine to what extent the conditions to which the athlete is exposed during the preceding cycle (frontal area presented to the wind, terrain, gearing, pedalling cadence, and intensity) can affect subsequent running speed and/or efficiency; $(b)$ to investigate the effects on running performance off the bike of the back to back training methods proposed above for junior and elite triathletes; (c) to investigate the effect of varying parameters - for example, volume, intensity, frequency, recovery type, and durationduring the cycle and running sections of back to back sessions on subsequent training adaptation; $(d)$ to investigate the extent to which back to back training may act as an extrinsic risk factor for overtraining, as evidenced by injury and illness.

\section{Conclusion}

Triathlon is more than the sum of its parts. It can be defined as "one sport, three disciplines and two transitions". Specific biomechanical, physiological, and sensorial adaptations are required for the second, cycle to run, transition. The ability to link the cycle and run section optimally results in improved running efficiency. The need for cycle to run transition training in elite triathletes is not clear, although the principle of specificity implies that they should practice during training what they will encounter during competition. Several reasons support the premise of an advantage in junior triathletes to practising back to back training regularly. Additional research is needed on both the need to integrate back to back training in the programme of elite and junior triathletes and the optimal methods of doing so.

Contributors: G P M initiated the review, discussed core ideas, proposed the main practical recommendations and wrote the paper. V E V discussed core ideas, added supplementary data, and participated in the writing of the paper. GP M is identified as the guarantor for this paper and is prepared to take public as the guarantor for
responsibility for it.

1 Farber H, Schaefer E, Franey R, et al. The endurance triathlon: metabolic changes after each event and during recovery. Med Sci Sports Exerc 1991;23:959-65.

2 Kohrt WM, Morgan DW, Bates B, et al. Physiological responses of triathletes to maximal swimming, cycling, and running. Med Sci Sports Exerc 1987;19:51-5.

3 Kreider R, Boone T, Thompson W, et al. Cardiovascular and thermal responses of triathlon performance. Med Sci Sports Exerc 1988;20:385-90.

4 O'Toole ML, Douglas PS. Applied physiology of triathlon. Sports Med 1995;19:251-67.

5 Sleivert G, Wenger H. Physiological predictors of shortcourse triathlon performance. Med Sci Sports Exerc 1993;25:871-6.

6 Sleivert GG, Rowlands DS. Physical and physiological factors associated with success in the triathlon. Sports Med 1996;22:8-18.
7 Zhou S, Robson SJ, King MJ, et al. Correlations between short-course triathlon performance and physiological variables determined in laboratory cycle and
Sports Med Phys Fitness 1997;37:122-30.

8 Mayers M, Holland G, Rich G, et al. Effects of prolonged intense cycle ergometry upon immediately subsequent maximal treadmill running in trained triathletes. Med Sci Sports Exerc 1986;18(suppl):S86(abstract 426).

9 Van Rensburg JP, Kielblock AJ, Van der Linde A. Physiological and biomechanical changes during a triathlon competition. Int $\mathcal{F}$ Sports Med 1986;7:30-5.

10 Miura H, Kitagawa K, Ishiko T. Economy during a simulated laboratory test triathlon is highly related to Olympic distance triathlon. Int f Sports Med 1997;18:27680 .

11 De Vito G, Bernardi M, Sproviero E, et al. Decrease of endurance performance during Olympic-triathlon. Int $\mathcal{f}$ Sports Med 1995;16:24-8.

12 Hue O, Le Gallais D, Chollet D, et al. The influence of prior cycling on biomechanical and cardiorespiratory response profiles during running in triathletes. Eur $\mathcal{F}$ Appl Physiol 1998;77:98-105.

13 Margaritis I. Facteurs limitants de la performance en triathlon. Canadian fournal of Applied Physiology 1996;21: $1-15$.

14 Borchers GE, Buckenmeyer PJ. Triathlon: The swim to bicycle transition. Med Sci Sports Exerc 1987;19(suppl): S49 (abstract 293)

15 Lepers R, Bigard AX, Hausswirth C, et al. Modélisation de l'enchaînement natation-cyclisme d'un triathlon en laboratoire. Influence sur la cinétique de la lactatémie. Science et Sports 1995;10:131-9.

16 Boone T, Kreider RB. Bicycle exercise before running: effect on performance. Annals of Sports Medicine 1986;3: $25-9$.

17 Danner T, Plowman SA. Running economy following an intense cycling bout in female duathletes and triathletes. WSPAF 1995;3:29-39.

18 Hausswirth C, Bigard AX, Guezennec CY. Relationships between running mechanics and energy cost of running at between running mechanics and energy cost of running at
the end of a triathlon and a marathon. Int $\mathcal{f}$ Sports Med 1997; 18:330-9.

19 Quigley EJ, Richards JG. The effects of cycling on running mechanics. Fournal of Applied Biomechanics 1996;12: $470-9$

20 Witt M. Co-ordination of leg muscles during cycling and running in triathlon. XIVth Congress of International Society of Biomechanics. Paris, 1993;1470-1.

21 Pfützner A, Grosse S. L'entrainement aux enchaînements: objectif majeur de l'entrainement spécifique en triathlon. In: Lehenaff $\mathrm{D}$, Helal $\mathrm{H}$, eds. Un sport, deux enchaînements, trois disciplines: le triathlon. Actes du premier symposium international de l'entrainement en triathlon. Les cahiers de l'INSEP 1997;20:143-5.

22 Guezennec CY, Vallier JM, Bigard AX, et al. Increase in energy-cost of running at the end of a triathlon. Eur $\mathcal{F} A p p l$ Physiol 1996;73:440-5.

23 Hausswirth C, Bigard AX, Berthelot M, et al. Variability in energy-cost of running at the end of a triathlon and a marathon. Int $\mathcal{F}$ Sports Med 1996;17:572-9.

24 Caillaud C, Serrecousine O, Anselme F, et al. Computerized-tomography and pulmonary diffusingcapacity in highly trained athletes after performing a triathlon. f Appl Physiol 1995;79:1226-32.

25 Marino GW, Goegan J. Work-energy analysis of triathletes running under bike/run and run only conditions. Proceedings of the XIth symposium of the International Society of Bioings of the XIth symposium of the International
mechanics in Sport, Amherst, $M A$ 1993:86-8.

26 Kreider R, Cundiff D, Hammett J, et al. Effects of cycling on running performance in triathletes. Annals of Sports Medicine 1988:3:220-5.

27 Hausswirth, C, Lehénaff D, Dréano P, et al. Effects of cycling alone or in a sheltered position on subsequent running performance during a triathlon. Med Sci Sports Exerc 1999;31:599-604.

28 Smith, D. Power demands of the cycle leg during elite triathlon competition. In: Lehenaff $\mathrm{D}$, ed. 2nd INSEP International Triathlon Congress. Les cahiers de l'INSEP 1999;24:224-32.

29 Williams KR, Snow R, Agruss C. Changes in distance running kinematics with fatigue. International fournal of Sports Biomechechanics 1991;7:138-62.

30 Candau R, Belli A, Millet GY, et al. Energy cost and running mechanics during a treadmill run to voluntary exhaustion mechanics during a treadmill run to voluntary
in humans. Eur f Appl Physiol 1998;77:479-85.

31 Millet GP, Millet GY, Hoffman MD, et al. Alterations in running economy and mechanics after maximal cycling in triathletes: Influence of performance level. Int $\mathcal{F}$ Sports Med 2000;21:1-6.

32 Millet GP, Millet GY, Candau RB, et al. Modifications des coûts énergétique et mécanique de la course à pied dans trois populations de triathlètes. In: $1^{\text {er }}$ symposium "Triathlon Sydney 2000”. Paris: INSEP, 1998:50-9.

33 Nicol C, Komi PV, Horita T, et al. Reduced stretch-reflex sensitivity after exhausting stretch-shortening cycle exercise. Eur F Appl Physiol 1996;72:401-9.

34 Lepers R, Bigard AX, Diard JP, et al. Posture control after prolonged exercise. Eur F Appl Physiol 1997;76:5561.

35 Zderic TW, Ruby BC, Hartpence W, et al. Physiological predictors of combined cycling and running performance in trained male triathletes. Med Sci Sports Exerc 1997; 29(suppl):S221 (abstract 1262). 
36 Palmer GS, Noakes TD, Hawley JA. Effects of steady-state versus stochastic exercise on subsequent cycling performversus stochastic exercise on subsequent
ance. Med Sci Sports Exerc 1997;29:684-7.

37 O'Toole ML. Training for ultraendurance triathlons. Med Sci Sports Exerc 1989;21:S209-13.

38 Ruby B, Robergs R, Leadbetter G, et al. Cross-training between cycling and running in untrained females. F Sports Med Phys Fitness 1996;36:246-54.
39 Vleck VE, Garbutt G. Injury and training characteristics of male elite, development squad and club triathletes. Int $\mathcal{F}$ Sports Med 1998;19:38-42.

40 Bompa TO. Theory and methodology of training: the key to athletic performance. Dubuque, IO: Kendall Hunt Publishing Company, 1994

41 Millet G. Les enchainements du jeune athlète "multisports". Revue EPS 1998;274:33-5.

Take home message

The cycle to run transition in triathlon elicits physiological, biomechanical, and sensorial adaptations, which alter the running efficiency. Elite triathletes are "less altered" than their subelite counterparts. Specific back to back cycle-run training sessions would be beneficial for juniors and beginners.

\section{Commentary}

For anyone who has participated in a triathlon, the feelings accompanying the cycle to run transition (T2 transition) will be all too familiar and painful. For the elite and juniors, the difference between success or failure at this adaptation may well determine the overall results in a race.

The authors have covered this topic comprehensively and detail factors that may contribute to the increased energy cost of running after cycling when compared with control running. No research to date has looked at those triathletes who spend very little time in T2 transition and compared their energy cost for running with those that spend longer in T2 transition. Whether they are better adapted, and run faster, or gain time by a faster transition is unclear, but the authors show that they race faster.

The authors emphasise that economy of effort in the cycle section of a drafting legal race will minimise the stochastic power output. This necessitates the triathlete riding near to the front of the pack of cyclists. Drafting behind the lead cyclists confers an energy saving, but the ideal position should not be too far back in the pack, so avoiding excessive braking at corners and hence a rise in the stochastic power output. Being "pack wise" is important then for energy conservation and will influence the physiological changes required for commencing the run.

Neurosensory, musculoskeletal, cardiovascular, and psychological habituation to T2 transitions are clearly the desired end points of appropriate training regimens. Quite what those training regimens should be has yet to be accurately determined. In the competitive world of triathlon perhaps the results, if established, will never be published!

ROD JAQUES

Medical Adviser British Triathlon Association The Winfield Hospital, Gloucester 